\title{
1 Lassa and Ebola virus inhibitors identified using minigenome and recombinant virus reporter
}

2 systems

3 Stephen R Welch ${ }^{1}$, Lisa Wiggleton Guerrero ${ }^{1}$, Ayan K. Chakrabarti ${ }^{1}$, Laura K. McMullan ${ }^{1}$, Mike Flint ${ }^{1}$, Gregory

4 R. Bluemling ${ }^{2}$, George R. Painter ${ }^{2}$, Stuart T. Nichol ${ }^{1}$, Christina F. Spiropoulou ${ }^{1}$, and César G. Albariño ${ }^{\text {* }}$

$5 \quad$ Viral Special Pathogens Branch, Division of High-Consequence Pathogens and Pathology, National Center for

6 Emerging and Zoonotic Infectious Diseases, Centers for Disease Control and Prevention, 1600 Clifton Road, MG

7 G-14, Atlanta, GA 30329, USA

$8 \quad{ }^{2}$ Emory Institute for Drug Development, Emory University, Atlanta, GA, USA

9 *Corresponding author. Tel.: +1 404639 1584. Email: bwu4@cdc.gov (C.G. Albariño)

10

11

12

(C) 2016. This manuscript version is made available under the Elsevier user license

http://www.elsevier.com/open-access/userlicense/1.0/ 


\section{Abstract}

14 Lassa virus (LASV) and Ebola virus (EBOV) infections are important global health issues resulting in 15 significant morbidity and mortality. While several promising drug and vaccine trials for EBOV are 16 ongoing, options for LASV infection are currently limited to ribavirin treatment. A major factor impeding 17 the development of antiviral compounds to treat these infections is the need to manipulate the virus 18 under BSL-4 containment, limiting research to a few institutes worldwide. Here we describe the 19 development of a novel LASV minigenome assay based on the ambisense LASV S segment genome, 20 with authentic terminal untranslated regions flanking a ZsGreen (ZsG) fluorescent reporter protein and 21 a Gaussia princeps luciferase (gLuc) reporter gene. This assay, along with a similar previously established EBOV minigenome, was optimized for high-throughput screening (HTS) of potential antiviral compounds under BSL-2 containment. In addition, we rescued a recombinant LASV expressing ZsG, which, in conjunction with a recombinant EBOV reporter virus, was used to confirm any potential antiviral hits in vitro. Combining an initial screen to identify potential antiviral compounds at BSL-2 containment before progressing to HTS with infectious virus will reduce the amount of expensive and technically challenging BSL-4 containment research. Using these assays, we identified 6-azauridine as having anti-LASV activity, and demonstrated its anti-EBOV activity in human cells. We further identified 2'-deoxy-2'-fluorocytidine as having potent anti-LASV activity, with an EC $_{50}$ value 10 times lower than that of ribavirin. 


\section{Introduction}

Lassa virus (LASV) and Ebola virus (EBOV) cause viral hemorrhagic fevers (VHFs) associated with substantial mortality and morbidity (Geisbert and Jahrling, 2004). LASV (family Arenaviridae) is endemic in West Africa, with an estimated 100,000-300,000 annual cases and 5,000 deaths (McCormick and Fisher-Hoch, 2002). EBOV (family Filoviridae) is responsible for recurring epidemics in Africa, including the 2013-2016 outbreak in West Africa that resulted in over 28,000 cases (World Health Organisation, 2016). No vaccines or therapeutics are currently approved for the prevention or treatment of either infection, leaving supportive care or "off-label" use of existing drugs the only options for health care workers (Geisbert and Jahrling, 2004; Jacobs et al., 2015).

The requirement to handle these viruses at biosafety level 4 (BSL-4) limits research to only a few institutions worldwide. In lieu of using live virus at BSL-4, many groups have used virus-like particles containing the LASV or EBOV envelope glycoproteins, or pseudotyped lentivirus or vesicular stomatitis virus particles to study viral entry or egress and to screen inhibitors of these processes (Anantpadma et al., 2016; Han et al., 2014; Kouznetsova et al., 2014; Maisa et al., 2009; Yonezawa et al., 2005). One largely unexplored option is the identification of antivirals targeting viral replication and transcription; using nucleoside analogs to inhibit these processes has proven highly successful for other viral infections, such as HIV and hepatitis C virus (HCV) (Cihlar and Ray, 2010; Gane et al., 2013). Minigenome assays emulate viral replication and transcription, and may be used to identify inhibitors of these processes (McCarthy et al., 2016; Uebelhoer et al., 2014). However, while the signal generated by a minigenome is dependent on its replication by viral proteins, the expression of these proteins, usually from co-transfected plasmids, requires cellular factors like RNA polymerase II (PollI). Thus, the activity of compounds identified during screening using a minigenome system must be confirmed in additional assays using infectious virus.

Here we describe the development of a LASV minigenome assay that can be performed at BSL-2. We also generated a novel recombinant LASV expressing the fluorescent reporter protein ZsGreen (ZsG) to facilitate high-throughput screening (HTS) compound testing at BSL-4. We used these novel LASV minigenome and reporter virus assays alongside the existing EBOV assays (Albariño et al., 2016; Albariño et al., 2015) to test the ability of 27 selected commercially available nucleoside analogs to inhibit LASV and EBOV minigenome function. We verified the specificity of these compounds using reporter and authentic wild-type viruses.

\section{Materials and Methods}

\subsection{Biosafety}


Work with infectious wild-type and recombinant LASV and EBOV was performed under BSL-4 containment. Experiments involving cDNA encoding viral sequences were performed in accordance with approved Institutional Biosafety Committee (IBC) protocols. Minigenome experiments were conducted under BSL-2 conditions.

\subsection{Cell culture, viruses, and compounds}

Huh7 cells (Apath), Vero-E6 cells, and BSR-T7/5 cells were cultured in Dulbecco's modified Eagle's medium (DMEM) supplemented with 5\% (v/v) fetal calf serum (FCS), $100 \mathrm{U} / \mathrm{mL}$ penicillin, and 100 $\mu \mathrm{g} / \mathrm{mL}$ streptomycin. Huh7 cells were further supplemented with $1 \times$ non-essential amino acids (NEAA). BSR-T7/5 cells were selected with $1 \mathrm{mg} / \mathrm{mL}$ G418 (Invitrogen) added every other passage. The viruses used in generating the recombinant strains were LASV (Strain Josiah, Genbank HQ688673.1, HQ688675.1) and EBOV (Zaire ebolavirus strain Ebola virus/H.sapiens-rec/LBR/2014/Makona-L2014, Genbank KR781608). Nucleoside analogs were obtained from Sigma-Aldrich, Selleckchem, U.S. Pharmacopeia, Carbosynth, and Emory Institute of Drug Development (EIDD).

\subsection{Rescue of $r L A S V / Z s G$ reporter virus}

To rescue recombinant LASV expressing ZsG (rLASV/ZsG), BSR-T7/5 cells were transfected with plasmids containing full-length, antigenomic-sense LASV $L$ and recombinant $S$ genome segments under transcriptional control of a T7 promoter element. The recombinant S segment contained the inserted ZsG-P2A coding sequence immediately $5^{\prime}$ to the nucleoprotein (NP) coding sequence. The P2A sequence causes self-cleavage of the nascent peptide chain during translation, resulting in the expression of the 2 separate proteins, ZsG and NP (Kim et al., 2011). Cells were transfected with $1 \mu \mathrm{g}$ of each plasmid, and 5 days post transfection the supernatant was removed and used to infect Vero-E6 cells as previously described (Albariño et al., 2015). rLASV/ZsG tissue culture infective dose 50 $\left(T_{C I D}\right)$ titers were determined in Vero-E6 cells by immunofluorescence assays using anti-LASV polyclonal antibodies.

\subsection{Minigenome and reporter virus assay screening of nucleoside analogs}

For minigenome screening, Huh7 cells were seeded $2 \times 10^{4}$ cells/well in a 96-well plate 1 day prior to the assay. The plasmids used in the assay were pLASV-S (ZsG/gLuc), which expresses the minigenome segment, and the support plasmids pC-LASV-L and pC-LASV-NP, which express LASV 
polymerase (L) and NP respectively. The minigenome is based on the LASV S segment, in which the NP and GPC coding sequences have been replaced with those of ZsG and Gaussia princeps luciferase (gLuc), respectively, leaving the authentic untranslated regions and intergenic regions unchanged. The support plasmids express the viral proteins required for replication and transcription. $50 \mathrm{ng}$ of pLASV-S (ZsG/gLuc), $10 \mathrm{ng}$ of $\mathrm{pC}-\mathrm{LASV}-\mathrm{L}$, and $30 \mathrm{ng}$ of $\mathrm{pC}$-LASV-NP were transfected per well using $0.27 \mu \mathrm{L}$ TransIT-LT-1. One hour post transfection (hpt), nucleoside analogs diluted in DMSO were added to the cells (final DMSO concentration $0.5 \%$ ) and incubated for $48 \mathrm{~h}$ before gLuc expression was quantified using Renilla Luciferase Assay System (Promega). Luminescence was measured using a microplate reader (BioTek Synergy H1MD), with levels recorded at a height of $6 \mathrm{~mm}$ after a $2 \mathrm{~s}$ delay, $10 \mathrm{~ms}$ integration, and 75 gain/sensitivity for LASV minigenome and 50 gain/sensitivity for EBOV minigenome.

For reporter virus assays, Huh7 cells were seeded $1 \times 10^{4}$ cells/well of a 96-well plate in Fluorobrite cell culture media (Thermo Fisher) 1 day prior to the assay. Nucleoside analogs were added to the cells $1 \mathrm{~h}$ before infection with reporter virus ( $\mathrm{MOI}=0.1)$. Cells were incubated for $72 \mathrm{~h}$ before $\mathrm{ZsG}$ fluorescence levels were determined using a BioTek Synergy reader (height 6 mm; 120 gain/sensitivity). Cell viability was determined concurrently for both minigenome and reporter virus assays on compound-treated, mock transfected/infected cells using CellTiter-Glo (Promega), which measures cellular ATP content. All experiments were conducted in quadruplicate, and all values normalized to mock transfected/treated cells (i.e., DMSO only) for analysis.

\subsection{Virus titer reduction assay}

Huh7 cells were seeded $1 \times 10^{4}$ cells/well of a 96 -well plate 1 day prior to the assay. Cells were treated with the compound for $1 \mathrm{~h}$ prior to infection at $\mathrm{MOI}=0.1 ; 3$ days later, cell culture supernatants were harvested and virus titrations were performed in Vero-E6 cells. Three days after infection, the cells were fixed, permeabilized, and stained with virus-specific polyclonal antibodies to visualize viral proteins. The $T C I D_{50}$ of each sample was calculated using the Reed-Muench method (Reed and Muench, 1938).

\subsection{Data analysis}

Normalized values of both gLuc and ZsG expression were used to fit a 4-parameter equation to semilog plots of the concentration-response data, and to interpolate the nucleoside analog concentration that inhibited $50 \%$ of the gLuc or ZsG expression $\left(\mathrm{EC}_{50}\right)$ in transfected or infected cells, respectively. Cell viability data were similarly used to derive the $50 \%$ cytotoxicity concentration of each compound $\left(\mathrm{CC}_{50}\right)$. 
The selectivity index $(\mathrm{SI})$ was calculated by dividing the $\mathrm{CC}_{50}$ by the $\mathrm{EC}_{50}$. All analyses were performed using GraphPad Prism (GraphPad Software). Z prime (Z') score, a measure of statistical effect size, was calculated for each assay as a measure of suitability for HTS, with anything between 0.5 and 1.0 being considered acceptable (Zhang et al., 1999).

\section{Results}

\subsection{Design and optimization of a LASV minigenome for HTS of nucleoside analogs}

A LASV minigenome pC-LASV-S (ZsG/gLuc) was designed using a modified S segment in which the NP and GPC coding sequences were replaced with those for ZsG and gLuc, respectively (Figure 1a). Using 2 reporters allows for rapid qualification of minigenome activity by visualizing the cells under fluorescent microscopy, but further permits a more sensitive quantification of activity via measurement of expressed gLuc in the media. The HTS assays described here used the gLuc signal because of its higher sensitivity. A ratio of 3:1:5 of pC-LASV-S (ZsG/gLuc), pC-LASV-L, and pC-LASV-NP gave the optimal signal-to-noise ratio of $\sim 200: 1$ at $48 \mathrm{hpt}$ (Supplementary Figure 1). GLuc expression was detectable in the absence of LASV polymerase ( 60-fold over mock-transfected cells at $48 \mathrm{hpt}$; data not shown), and was likely the result of cryptic cellular RNA Polll promoters in the minigenome plasmid (Boehmann et al., 2005; Jasenosky et al., 2010; Muhlberger et al., 1999; Uebelhoer et al., 2014). Here, we used gLuc expression in the absence of polymerase (or, in the case of the EBOV minigenome, with an inactive form of EBOV polymerase [Albariño et al., 2016]) to evaluate the ability of compounds to inhibit cellular transcription mechanisms. Titrations of ribavirin, a guanosine analog with known activity against RNA virus replication (McCormick et al., 1986; Uebelhoer et al., 2014), were used to evaluate both minigenome assays in a 96-well format (Figures $1 \mathrm{~b}$ and 1c). Two measures of selectivity were used to assess the inhibitory activity of ribavirin. First, the SI value $\left(\mathrm{CC}_{50} / \mathrm{EC}_{50}\right)$ was calculated to obtain a ratio between the antiviral activity of a compound and its cytotoxicity. Second, we also calculated the ratio of the background $\mathrm{EC}_{50}$ value (defined as the concentration at which gLuc expression in the minigenome assay without an active polymerase was reduced by $50 \%$ ) to the $\mathrm{EC}_{50}$ value of the minigenome with an active polymerase; this was termed the $\mathrm{SI}_{\text {pol }}$ value. $\mathrm{SI}_{\text {pol }}$ was used to determine if minigenome inhibition was specific to the viral polymerase; if the inhibitory activity of a nucleoside was mediated through the inhibition of cellular RNA Polll, then the inhibition of the background signal would also be observed, giving an $\mathrm{SI}_{\text {pol }}$ value of approximately 1. Ribavirin concentration-dependent inhibition was observed in both LASV and EBOV minigenomes, with $\mathrm{EC}_{50}$ values of 2.51 and $5.04 \mu \mathrm{M}$, respectively (Figure 1d). For both assays, the $S I_{\text {pol }}$ value was $>20$, indicating specific inhibition of the viral polymerase. The $\mathrm{EC}_{50}$ values were lower than those previously reported (Hass et al., 2004; Oestereich et al., 2016; Uebelhoer et al., 2014), although this discrepancy may be due to differences 
162 between the minigenome designs and cell lines used. Using $50 \mu \mathrm{M}$ ribavirin as the positive control and 163 DMSO vehicle-only signal as the negative control, the Z' scores were calculated to be 0.86 for LASV 164 minigenome and 0.60 for EBOV minigenome assays. These scores indicated the suitability of both 165 minigenomes to be used in HTS assays.

166 Next, we tested the ability of 27 selected nucleoside analogs to inhibit the LASV and EBOV 167 minigenomes, using 3 concentrations of each compound (5000, 500, and $50 \mathrm{nM}$; Supplementary Table 168 1). Using a cut-off of $<15 \%$ minigenome activity compared to the mock-treated control, we selected for 169 further evaluation 6 compounds that inhibited activity of LASV minigenome and 3 that inhibited activity 170 of the EBOV minigenome. Titrations were then performed for these compounds using the respective 171 minigenomes (Figure 2). Any inhibitory effects of 8-azidoadenosine on LASV minigenome activity and 172 toyocamycin on EBOV minigenome activity were difficult to distinguish from the associated cytotoxicity. 173 Toyocamycin, 5-fluorouridine and 8-azaadenosine reduced the LASV minigenome signal in a 174 concentration-dependent manner without cytotoxicity, but also concomitantly inhibited background gLuc 175 expression in the absence of viral $\mathrm{L}$ polymerase. The $\mathrm{SI}_{\text {pol }}$ values of these compounds ranged from 1-2 176 indicating an indirect inhibitory mechanism.

177 In contrast, 6-azaurdine and 2'-deoxy-2'-fluorocytidine (2'-dFC) reduced minigenome signal without 178 affecting background gLuc levels. 6-azauridine, which was previously shown to block EBOV and 179 Marburg virus minigenome activity in BSR-T7/5 cells (Uebelhoer et al., 2014), inhibited both LASV and 180 EBOV minigenomes with $\mathrm{EC}_{50}$ values of 4.76 and $3.88 \mu \mathrm{M}$, respectively. 2'-dFC inhibited the LASV 181 minigenome with an $\mathrm{EC}_{50}$ value of $1.35 \mu \mathrm{M}$. Neither drug was cytotoxic at the highest concentration 182 tested. $\mathrm{SI}_{\text {pol }}$ values $>10$ for both compounds indicated that they acted specifically on viral proteins, and 183 not indirectly by inhibiting cellular polymerases such as RNA Polll.

\subsection{Generation of rLASV/ZsG reporter virus}

186 To further evaluate the efficacy of the compounds against authentic viral replication and transcription, 187 we used recombinant LASV and EBOV, both expressing ZsG. The development of the reporter EBOV 188 has been described previously (Albariño et al., 2015). Generating recombinant arenaviruses expressing 189 foreign proteins, however, is complicated by the compact nature of the genome, which lacks nonessential elements that can be replaced with a reporter gene. One previous attempt to generate a reporter arenavirus lymphocytic choriomeningitis virus (LCMV) incorporated an additional third genome segment containing a reporter protein coding sequence (Emonet et al., 2009). A similarly designed recombinant LASV was rescued, but grew poorly and lost the reporter segment after 2-3 passages (unpublished data). However, fusing a fluorescent reporter protein, such as ZsG, to the $\mathrm{N}$-terminus of a 
viral protein (with the P2A peptide linkage sequence from porcine teshovirus-1) resulted in successful rescue of the reporter EBOV and also a reporter LCMV expressing GFP (Ngo et al., 2015). Incorporating P2A results in self-cleavage and the expression of 2 proteins from a single promoter (Kim et al., 2011). Using this approach, we generated the recombinant rLASV/ZsG virus, in which the ZsGP2A coding sequence was inserted at the $N$ terminus of LASV NP (Figure 3a). The recombinant viruses were successfully rescued in BSR-T7/5 cells, with ZsG expression detected in Huh7 cells at $72 \mathrm{hpi}$ using $\mathrm{MOI}$ of 0.1 of both viruses (Figure $3 b$ ). Characterization of the growth kinetics of rLASV/ZsG versus the wildtype Josiah strain showed modest attenuation of the recombinant virus, with titers reduced by approximately 1 log at $72 \mathrm{hpi}$; however, ZsG expression was sufficient to quantify using a fluorescence plate reader, allowing its use in HTS (Figure 3c). To evaluate the suitability of rLASV/ZsG and $\mathrm{rEBOV} / \mathrm{ZsG}$ for HTS, a dose-response curve was performed for both viruses using ribavirin. Concentration-dependent reduction of ZsG fluorescence was observed in cells infected with both $\mathrm{rLASV} / \mathrm{ZsG}$ and $\mathrm{rEBOV} / \mathrm{ZsG}$, with $\mathrm{EC}_{50}$ values of 2.03 and $5.34 \mu \mathrm{M}$, respectively, and no associated loss in cell viability (Figures $3 \mathrm{c}$ and $3 \mathrm{~d}$ ). The signal-to-noise ratios for $\mathrm{rLASV} / \mathrm{ZsG}$ and $\mathrm{rEBOV} / \mathrm{ZsG}$ were $32: 1$ and $87: 1$, respectively. Using $50 \mu \mathrm{M}$ ribavirin as the positive control and DMSO vehicle-only signal as the negative control, the $Z^{\prime}$ scores were 0.84 for rLASV/ZsG and 0.75 for $\mathrm{rEBOV} / \mathrm{ZsG}$, indicating the suitability of both reporter virus assays to be used for HTS of compounds.

\subsection{Evaluating antiviral characteristics of selected nucleoside analogs}

As 6-azauridine and 2'-dFC had $\mathrm{SI}_{\text {pol }}$ values $>10$, they were selected for further testing using the reporter virus assays. Dose-response assays were performed with the nucleoside analogs in Huh7 cells infected with $\mathrm{MOI}=0.1$ of either $\mathrm{rLASV} / Z \mathrm{sG}$ or $\mathrm{rEBOV} / \mathrm{ZsG}$. Inhibition was quantified by measuring ZsG fluorescence at $3 \mathrm{dpi}$. A dose-dependent reduction in fluorescence was observed in 6azauridine treated cells for $\mathrm{rLASV} / \mathrm{ZsG}$ and $\mathrm{rEBOV} / \mathrm{ZsG}\left(\mathrm{EC}_{50}: 10.95 \mu \mathrm{M}\right.$ for $\mathrm{rLASV} / \mathrm{ZsG}, 11.32 \mu \mathrm{M}$ for rEBOV/ZsG; Figure 4a). Similarly, a reduction in fluorescence was observed in 2'-dFC treated cells infected with rLASV/ZsG, with an $\mathrm{EC}_{50}$ of $226 \mathrm{nM}$ (Figure 4b). To confirm that antiviral activity of the nucleoside analogs was not specific to the ZsG-expressing viruses, the compounds were tested against wild-type LASV and EBOV. Both reduced wild-type virus titers in a concentration-dependent manner (Figure 4c): at the highest concentrations used, both compounds reduced the titers of their respective viruses by approximately 2 logs. The $\mathrm{EC}_{50}$ values of both the compounds tested against wild-type virus were lower than those determined when using the corresponding reporter virus. The chemical structures of 2'-dFC and 6-azauridine are shown in Figure 4d. 


\subsection{Evaluating inhibitory properties of anti-HIV nucleoside analogs against LASV and EBOV}

During the 2013-2016 EBOV disease epidemic in West Africa, reports emerged suggesting that the anti-HIV nucleoside analog lamivudine was effective in treating EBOV infection. Furthermore, a recent study reported that lamivudine and 3 other anti-HIV nucleoside analogs - stavudine, zidovudine, and tenofovir - inhibited an EBOV minigenome (McCarthy et al., 2016). Other studies, however, reported no inhibition of EBOV by lamivudine (Hensley et al., 2015). We assessed the antiviral activity of each above-mentioned anti-HIV compound using dose-response assays with both minigenomes and reporter viruses. All 4 compounds exhibited no cytotoxicity, but also showed little specific antiviral activity (Figure 5). Tenofovir inhibited both LASV and EBOV minigenomes, but this effect was non-specific, as gLuc expression in the absence of viral polymerase was similarly inhibited. Tenofovir also did not significantly inhibit either reporter virus even at the highest concentration used (50 $\mu \mathrm{M})$. Lamivudine showed no significant inhibition in any assay at the highest tested concentration $(50 \mu \mathrm{M})$.

\section{Discussion}

A significant problem hindering the study of hemorrhagic fever viruses is the need to conduct experiments under high containment. The ability to deconstruct the viral lifecycle into discrete functions is a useful tool, proving especially invaluable in the study of BSL-4 pathogens by allowing experiments to be performed at lower biosafety containment levels. Here we used LASV and EBOV minigenome assays to evaluate their potential as BSL-2 surrogates for both BSL-4 reporter virus and wild-type virus in HTS of antiviral compounds. To confirm any potential hits, we also developed a novel recombinant LASV expressing the ZsG reporter protein to complement the existing reporter EBOV. The activity of both the minigenome and the ZsG reporter virus can be quantified rapidly, in a non-destructive manner, and using the same plate reader, thus allowing large numbers of compounds to be screened simultaneously for activity against LASV and EBOV. During the recent EBOV outbreak the challenges of VHF outbreak management in a region with two hemorrhagic fever viruses circulating became apparent (Goba et al., 2016). Given that both infections can occur in overlapping geographic areas and present with similar initial clinical signs, obtaining an exact diagnosis is generally dependent upon molecular diagnostic assays. High-throughput screening of inhibitors targeting multiple VHF pathogens simultaneous will hopefully identify compounds active against both LASV and EBOV, thus allowing treatment to begin immediately upon suspicion of a VHF infection in known LASV/EBOV regions without having to wait for a definite diagnosis. 
Several compounds were identified by our screens as potentially having anti-EBOV and anti-LASV activity. A measure of selectivity, $\mathrm{SI}_{\mathrm{po}}$, was included to assess whether the inhibition of minigenome signal expression occurred through inhibition of the viral polymerases, or whether the putative antiviral compounds also blocked background luciferase signals in the absence of viral polymerase. 5fluorouridine, 8-azaadenosine, 8-azidoadenosine, toyocamycin, and tenofovir inhibited minigenome signals, but exhibited low $\mathrm{SI}_{\mathrm{pol}}$ values (<2), suggesting non-specific activity. This was consistent with their inhibition of cellular factors required for the function of the assay, possibly the cellular RNA polymerases required for transcription and expression from the minigenome plasmids. These findings highlight a potential issue with using minigenome systems alone for antiviral screening, as inhibitors of the system itself, rather than of viral polymerase-dependent processes, may be identified as hits. The $\mathrm{SI}_{\text {pol }}$ value may therefore be used to assess the specificity of inhibition and prioritize compounds for antiviral HTS in the more expensive and technically challenging BSL-4 containment.

Two compounds, 2'-dFC and 6-azauridine, had $\mathrm{Sl}_{\text {pol }}$ values $>10$, indicating that their mechanism of action may be virus-specific. 6-azauridine was previously shown to inhibit EBOV and Marburg virus (Uebelhoer et al., 2014). Here we demonstrated that 6-azauridine has anti-LASV activity, and confirmed its anti-EBOV activity in the human Huh7 cell line. Previous assays used golden hamster BSR-T7/5 cells, but human cells are preferred, especially for testing nucleoside analogues which, if acting through incorporation into viral RNA, need cellular factors to be phosphorylated to an active form. 6-azauridine is known to inhibit multiple viruses by blocking cellular pyrimidine biosynthesis (Chen and Jones, 1979; Flint et al., 2014; Lo et al., 2014; Uebelhoer et al., 2014). Its $\mathrm{SI}_{\text {pol }}$ value suggests that the LASV and EBOV polymerases may be more susceptible to this mechanism of inhibition than cellular RNA polymerases. 2'-dFC is an analog of PSI-6130, a potent inhibitor of HCV (Murakami et al., 2007; Stuyver et al., 2006), differing from PSI-6130 by the absence of a methyl group at the 2' position (Figure $4 \mathrm{~d}$ and Supplementary Figure 2). The addition of the methyl group lowered the $\mathrm{EC}_{90}$ value against an HCV replicon from $6.5 \mu \mathrm{M}$ with 2'-dFC to $4.6 \mu \mathrm{M}$ with PSI-6130. However, though PSI-6130 was included in our initial screen of analogs, it did not inhibit LASV minigenome activity, suggesting that this 2'-methyl group negatively affects compound effectiveness against LASV. Both our minigenome and reporter virus assays proved useful in examining recent reports concerning the effectiveness of the anti-HIV nucleoside analogs lamivudine, stavudine, zidovudine, and tenofovir against EBOV. Our data contradict previous reports by McCarthy et al. 2016, which showed that these compounds inhibited an EBOV minigenome. Other studies, however, showed no inhibition of EBOV by lamivudine (Hensley et al., 2015). Similarly, in our studies, none of these compounds showed specific anti-EBOV or anti-LASV activity.

In conclusion, we have described the development of LASV and EBOV minigenome and reporter virus assays adaptable to HTS of antiviral compounds. Furthermore, the use of identical reporter proteins 
295 and HTS methodologies described here for both of these pathogens should greatly facilitate compound 296 testing under BSL-4 containment. We have shown that the anti-EBOV activity of 6-azaurdine reported 297 in BSRT-7 cells is also observed in cells of human origin, and that this compound also has anti-LASV 298 activity. We have further shown that 2'-dFC potently inhibits LASV, much more so than ribavirin, which 299 is currently the only available treatment option for LASV infection. Further experimentation in animal 300 models will be needed to confirm the antiviral activity in vivo. We believe the findings from our study will 301 aid the development of badly needed antiviral agents against EBOV and LASV.

302

303 Acknowledgements

304 We thank Florine Scholte and Eric Bergeron for their technical assistance, and Tatyana Klimova for 305 assistance with editing this manuscript. The findings and conclusions in this report are those of the 306 authors and do not necessarily represent the official position of the CDC. Steve Welch holds a 307 fellowship supported by the Research Participation Program at the CDC administered by the Oak Ridge 308 Institute for Science and Education (ORISE) through an interagency agreement between the U.S. 309 Department of Energy (DOE) and CDC. 
311 Figure 1: Design and validation of the Lassa virus and Ebola virus minigenomes. a. Genome

312 schematics of the Lassa virus (LASV) and Ebola virus (EBOV) minigenome (MG) segments. The LASV

313 minigenome contains the antigenome 5' and 3' UTRs of LASV S segment (Strain Josiah,

314 Genbank HQ688673.1) in which the nucleocapsid protein (NP) and glycoprotein precursor (GPC)

315 coding sequences have been replaced with those for ZsGreen (ZsG) and Gaussia princeps luciferase

316 (gLuc), respectively. Support plasmids encode LASV polymerase (L) and NP. The EBOV minigenome

317 contains the antigenome 5' and 3' UTRs of Ebola (Zaire ebolavirus strain Ebola virus/H.sapiens-

$318 \mathrm{rec} / \mathrm{LBR} / 2014 /$ Makona-L2014, Genbank KR781608) flanking the gLuc coding sequence. Support

319 plasmids encode EBOV $L$ and NP, and transcriptional accessory proteins VP30 and VP35. b. The

320 optimized LASV and c. EBOV minigenome assays were evaluated with the antiviral compound

321 ribavirin. Reductions in gLuc expression in cells transfected with the minigenome and helper plasmids

322 including viral polymerase (blue) or without an active viral polymerase (red) were measured, with gLuc

323 values normalized to mock-treated cells (DMSO only). Cell viability was assessed at each ribavirin

324 concentration by measuring ATP content (green), and values were normalized to mock-treated cells.

325 Each point represents the mean of quadruplicate wells, with error bars indicating standard deviation;

326 graphs are representative of 2 independent experiments. d. EC 50 values for each compound, including

$327 \mathrm{EC}_{50}$ for inhibition of background gLuc expression in the assays not containing an active polymerase

$328\left(\mathrm{EC}_{50} \mathrm{BG}\right)$, along with $\mathrm{CC}_{50}$ and $\mathrm{SI}$ values. $\mathrm{SI}_{\mathrm{pol}}$ is the ratio of background $\mathrm{EC}_{50}$ to $\mathrm{EC}_{50}$ values.

Figure 2: Screening of potential anti-viral nucleoside analogs using minigenome assays.

331 Concentration-response curves in Huh7 cells for a. LASV and b. EBOV minigenome (MG) transfected

332 cells treated with nucleoside analogs. Reductions in gLuc expression in cells transfected with

333 minigenome and helper plasmids including viral polymerase (blue) or without an active viral polymerase

334 (red) were measured, with values normalized to mock-treated cells (DMSO only). Cell viability was

335 assessed at each compound concentration by measuring ATP content (green), and values were

336 normalized to mock-treated cells. Each point represents the mean of quadruplicate wells, with error

337 bars indicating standard deviation; graphs are representative of 2 independent experiments. c. $E_{50}$

338 values for each compound, including $\mathrm{EC}_{50}$ values for inhibition of background gLuc expression in the assays not containing an active polymerase $\left(\mathrm{EC}_{50} \mathrm{BG}\right)$, are stated along with $\mathrm{CC}_{50}$ and $\mathrm{SI}$ values. $\mathrm{SI}_{\mathrm{pol}}$ is the ratio of $\mathrm{EC}_{50} \mathrm{BG}: \mathrm{EC}_{50}$ values. $\mathrm{NT}=$ not tested.

Figure 3: Design and evaluation of reporter viruses. a. Schematic representation of the genomes of 
ZsG-P2A-VP40 coding sequence under transcriptional control of the parental VP40 promoter and terminator sequences. The P2A amino acid sequence self-cleaves, resulting in separate ZsG and VP40 proteins. Based on LASV strain Josiah (Genbank HQ688673.1, HQ688675.1), rLASV/ZsG contains a ZsG-P2A-NP coding sequence in the S segment. b. ZsG expression in Huh7 cells infected at MOI 0.1 with either rEBOV/ZsG or rLASV/ZsG 48 hpi. Cells imaged on an EVOS fluorescent microscope (Thermo Fisher), intensity 50\%, × 4 magnification. c. Characterization of growth kinetics of rLASV/ZsG versus wildtype LASV strain Josiah. Huh7 cells were infected at $\mathrm{MOI} 0.1$ and titers determined at each time point by $\mathrm{TCID}_{50}$. d. The optimized $\mathrm{rLASV} / \mathrm{ZsG}$ and $\mathrm{rEBOV} / \mathrm{ZsG}$ reporter virus assays were evaluated with the antiviral compound ribavirin. Reductions in ZsG fluorescence (blue) in infected cells were measured, with values normalized to mock-treated cells (DMSO only). Cell viability was assessed at each concentration by measuring ATP content (green), and values were normalized to mock-treated cells. Each point represents the mean of quadruplicate wells, with error bars indicating standard deviation; graphs are representative of 2 independent experiments. e. $\mathrm{EC}_{50}, \mathrm{CC}_{50}$, and SI values.

\section{Figure 4: Antiviral activity of 6-azauridine and 2'-deoxy-2'-fluorocytidine. a. Representative} concentration-response curves in Huh7 cells infected with either rLASV/ZsG or rEBOV/ZsG. Infected cells were treated with serial dilutions of either 6-azauridine or 2'-deoxy-2'-fluorocytidine (2'-dFC), and reduction in ZsG fluorescence (blue) was quantified; values were normalized to mock-infected cells. Cell viability was assessed at each concentration by measuring ATP content (green), and values were normalized to mock-treated cells. Each point represents the mean of quadruplicate wells, with error bars indicating standard deviation; graphs are representative of 2 independent experiments. NT $=$ not tested. b. Reduction in ZsG fluorescence in 2'-dFC treated Huh7 cells infected at MOI 0.1 with rLASV/ZsG 48 hpi. Cells imaged on an EVOS fluorescent microscope (Thermo Fisher), intensity 50\%, × 4 magnification. c. Titer reduction assays using wild-type LASV (strain Josiah, Genbank AY628203.1) and EBOV (Zaire ebolavirus strain Ebola virus/H.sapiens-rec/LBR/2014/Makona-L2014, Genbank KR781608). Huh7 cells were treated with varying concentrations of compound $1 \mathrm{~h}$ prior to infection with either LASV or EBOV at $\mathrm{MOI}=0.1$. Three days post infection, cell culture supernatants were collected, and virus titers $\left(\mathrm{TCID}_{50} / \mathrm{mL}\right)$ were determined in Vero-E6 cells by immunofluorescence assays. Mean titers are indicated, with errors bars representing standard deviation calculated from 3 independent infections. $\mathrm{EC}_{50}, \mathrm{CC}_{50}$, and SI values are stated for each compound. d. Chemical structure data for 2'$\mathrm{dFC}$ and 6-azauridine.

\section{Figure 5: Testing anti-HIV nucleoside analogs using minigenome assays and reporter viruses. a.}


379 minigenomes. Reduction in gLuc expression in cells transfected with minigenome and helper plasmids 380 including viral polymerase (blue) or without an viral active polymerase (red) was measured, with values 381 normalized to mock-treated cells (DMSO only). Cell viability was assessed for each concentration of 382 each compound by measuring ATP content (green); values were normalized to mock-treated cells. 383 Each point represents the mean of quadruplicate wells, with error bars indicating standard deviation; 384 graphs represent 2 independent experiments. $\mathrm{EC}_{50}$ values for each compound, including $\mathrm{EC}_{50}$ for 385 inhibition of background gLuc expression in the assays not containing an active polymerase (EC $\left.\mathrm{E}_{50} B G\right)$, 386 are stated, along with $\mathrm{CC}_{50}$ and $\mathrm{SI}$ values. $\mathrm{SI}_{\mathrm{pol}}$ is the ratio of $\mathrm{EC}_{50} \mathrm{BG}: \mathrm{EC}_{50}$ values. b. Representative 387 concentration-response curves in Huh7 cells infected with rLASV/ZsG or rEBOV/ZsG. Infected cells 388 were treated with serial dilutions of compound, and reduction in ZsG fluorescence (green) was 389 quantified; values were normalized to those from mock-infected cells. Each point represents the mean 390 of quadruplicate wells, with error bars indicating standard deviation. $\mathrm{EC}_{50}, \mathrm{CC}_{50}$, and $\mathrm{SI}$ values are 391 stated for each compound. 
Albariño, C.G., Guerrero, L.W., Chakrabarti, A.K., Kainulainen, M.H., Whitmer, S.L., Welch, S.R., Nichol, S.T., 2016. Virus fitness differences observed between two naturally occurring isolates of Ebola virus Makona variant using a reverse genetics approach. Virology 496, 237-243.

Albariño, C.G., Wiggleton Guerrero, L., Lo, M.K., Nichol, S.T., Towner, J.S., 2015. Development of a reverse genetics system to generate a recombinant Ebola virus Makona expressing a green fluorescent protein. Virology 484, 259-264.

Anantpadma, M., Kouznetsova, J., Wang, H., Huang, R., Kolokoltsov, A., Guha, R., Lindstrom, A.R., Shtanko, O., Simeonov, A., Maloney, D.J., Maury, W., LaCount, D.J., Jadhav, A., Davey, R.A., 2016. Large scale screening and identification of novel Ebolavirus and Marburgvirus entry inhibitors. Antimicrob Agents Chemother 60, 4471-4481.

Boehmann, Y., Enterlein, S., Randolf, A., Muhlberger, E., 2005. A reconstituted replication and transcription system for Ebola virus Reston and comparison with Ebola virus Zaire. Virology 332, 406417.

Chen, J.J., Jones, M.E., 1979. Effect of 6-azauridine on de novo pyrimidine biosynthesis in cultured Ehrlich ascites cells. Orotate inhibition of dihydroorotase and dihydroorotate dehydrogenase. J Biol Chem 254, 4908-4914.

Cihlar, T., Ray, A.S., 2010. Nucleoside and nucleotide HIV reverse transcriptase inhibitors: 25 years after zidovudine. Antiviral Res 85, 39-58.

Emonet, S.F., Garidou, L., McGavern, D.B., de la Torre, J.C., 2009. Generation of recombinant lymphocytic choriomeningitis viruses with trisegmented genomes stably expressing two additional genes of interest. Proc Natl Acad Sci U S A 106, 3473-3478.

Flint, M., McMullan, L.K., Dodd, K.A., Bird, B.H., Khristova, M.L., Nichol, S.T., Spiropoulou, C.F., 2014. Inhibitors of the tick-borne, hemorrhagic fever-associated flaviviruses. Antimicrob Agents Chemother 58, 3206-3216.

Gane, E.J., Stedman, C.A., Hyland, R.H., Ding, X., Svarovskaia, E., Symonds, W.T., Hindes, R.G., Berrey, M.M., 2013. Nucleotide polymerase inhibitor sofosbuvir plus ribavirin for hepatitis C. N Engl J Med 368, 34-44.

Geisbert, T.W., Jahrling, P.B., 2004. Exotic emerging viral diseases: progress and challenges. Nat Med 10, S110-121.

Goba, A., Khan, S.H., Fonnie, M., Fullah, M., Moigboi, A., Kovoma, A., Sinnah, V., Yoko, N., Rogers, H., Safai, S., Momoh, M., Koroma, V., Kamara, F.K., Konowu, E., Yillah, M., French, I., Mustapha, I., Kanneh, F., Foday, M., McCarthy, H., Kallon, T., Kallon, M., Naiebu, J., Sellu, J., Jalloh, A.A., Gbakie, M., Kanneh, L., Massaly, J.L., Kargbo, D., Kargbo, B., Vandi, M., Gbetuwa, M., Gevao, S.M., Sandi, J.D., Jalloh, S.C., Grant, D.S., Blyden, S.O., Crozier, I., Schieffelin, J.S., McLellan, S.L., Jacob, S.T., Boisen, M.L., Hartnett, J.N., Cross, R.W., Branco, L.M., Andersen, K.G., Yozwiak, N.L., Gire, S.K., Tariyal, R., Park, D.J., Haislip, A.M., Bishop, C.M., Melnik, L.I., Gallaher, W.R., Wimley, W.C., He, J., Shaffer, J.G., Sullivan, B.M., Grillo, S., Oman, S., Garry, C.E., Edwards, D.R., McCormick, S.J., Elliott, D.H., Rouelle, J.A., Kannadka, C.B., Reyna, A.A., Bradley, B.T., Yu, H., Yenni, R.E., Hastie, K.M., Geisbert, J.B., Kulakosky, P.C., Wilson, R.B., Oldstone, M.B., Pitts, K.R., Henderson, L.A., Robinson, J.E., Geisbert, T.W., Saphire, E.O., Happi, C.T., Asogun, D.A., Sabeti, P.C., Garry, R.F., Viral Hemorrhagic Fever, C., 2016. An Outbreak of Ebola Virus Disease in the Lassa Fever Zone. J Infect Dis.

Han, Z., Lu, J., Liu, Y., Davis, B., Lee, M.S., Olson, M.A., Ruthel, G., Freedman, B.D., Schnell, M.J., Wrobel, J.E., Reitz, A.B., Harty, R.N., 2014. Small-molecule probes targeting the viral PPxY-host Nedd4 interface block egress of a broad range of RNA viruses. J Virol 88, 7294-7306.

Hass, M., Golnitz, U., Muller, S., Becker-Ziaja, B., Gunther, S., 2004. Replicon system for Lassa virus. J Virol 78, 13793-13803.

Hensley, L.E., Dyall, J., Olinger, G.G., Jr., Jahrling, P.B., 2015. Lack of effect of lamivudine on Ebola virus replication. Emerg Infect Dis 21, 550-552.

Jacobs, M., Aarons, E., Bhagani, S., Buchanan, R., Cropley, I., Hopkins, S., Lester, R., Martin, D., Marshall, N., Mepham, S., Warren, S., Rodger, A., 2015. Post-exposure prophylaxis against Ebola virus 
disease with experimental antiviral agents: a case-series of health-care workers. Lancet Infect Dis 15, 1300-1304.

Jasenosky, L.D., Neumann, G., Kawaoka, Y., 2010. Minigenome-based reporter system suitable for high-throughput screening of compounds able to inhibit Ebolavirus replication and/or transcription. Antimicrob Agents Chemother 54, 3007-3010.

Kim, J.H., Lee, S.R., Li, L.H., Park, H.J., Park, J.H., Lee, K.Y., Kim, M.K., Shin, B.A., Choi, S.Y., 2011. High cleavage efficiency of a 2A peptide derived from porcine teschovirus-1 in human cell lines, zebrafish and mice. PLoS One 6, e18556.

Kouznetsova, J., Sun, W., Martinez-Romero, C., Tawa, G., Shinn, P., Chen, C.Z., Schimmer, A., Sanderson, P., McKew, J.C., Zheng, W., Garcia-Sastre, A., 2014. Identification of 53 compounds that block Ebola virus-like particle entry via a repurposing screen of approved drugs. Emerg Microbes Infect 3, e84.

Lo, M.K., Nichol, S.T., Spiropoulou, C.F., 2014. Evaluation of luciferase and GFP-expressing Nipah viruses for rapid quantitative antiviral screening. Antiviral Res 106, 53-60.

Maisa, A., Stroher, U., Klenk, H.D., Garten, W., Strecker, T., 2009. Inhibition of Lassa virus glycoprotein cleavage and multicycle replication by site 1 protease-adapted alpha(1)-antitrypsin variants. PLoS Negl Trop Dis 3, e446.

McCarthy, S.D., Majchrzak-Kita, B., Racine, T., Kozlowski, H.N., Baker, D.P., Hoenen, T., Kobinger, G.P., Fish, E.N., Branch, D.R., 2016. A rapid screening assay identifies monotherapy with interferon-ss and combination therapies with nucleoside analogs as effective inhibitors of Ebola virus. PLoS Negl Trop Dis 10, e0004364.

McCormick, J., Fisher-Hoch, S., 2002. Lassa fever,. Curr Top Microbiol Immunol 262, 75-109. McCormick, J.B., King, I.J., Webb, P.A., Scribner, C.L., Craven, R.B., Johnson, K.M., Elliott, L.H., Belmont-Williams, R., 1986. Lassa fever. Effective therapy with ribavirin. N Engl J Med 314, 20-26. Muhlberger, E., Weik, M., Volchkov, V.E., Klenk, H.D., Becker, S., 1999. Comparison of the transcription and replication strategies of marburg virus and Ebola virus by using artificial replication systems. J Virol 73, 2333-2342.

Murakami, E., Bao, H., Ramesh, M., McBrayer, T.R., Whitaker, T., Micolochick Steuer, H.M., Schinazi, R.F., Stuyver, L.J., Obikhod, A., Otto, M.J., Furman, P.A., 2007. Mechanism of activation of beta-D-2'deoxy-2'-fluoro-2'-C-methylcytidine and inhibition of hepatitis $C$ virus NS5B RNA polymerase. Antimicrob Agents Chemother 51, 503-509.

Ngo, N., Cubitt, B., Iwasaki, M., de la Torre, J.C., 2015. Identification and mechanism of action of a novel small-molecule inhibitor of arenavirus multiplication. J Virol 89, 10924-10933.

Oestereich, L., Rieger, T., Ludtke, A., Ruibal, P., Wurr, S., Pallasch, E., Bockholt, S., Krasemann, S., Munoz-Fontela, C., Gunther, S., 2016. Efficacy of favipiravir alone and in combination with ribavirin in a lethal, immunocompetent mouse model of Lassa fever. J Infect Dis 213, 934-938.

Reed, L.J., Muench, H., 1938. A simple method of estimating fifty per cent endpoints. Am J Epidemiol 27, 493-497.

Stuyver, L.J., McBrayer, T.R., Tharnish, P.M., Clark, J., Hollecker, L., Lostia, S., Nachman, T., Grier, J., Bennett, M.A., Xie, M.Y., Schinazi, R.F., Morrey, J.D., Julander, J.L., Furman, P.A., Otto, M.J., 2006. Inhibition of hepatitis $C$ replicon RNA synthesis by beta-D-2'-deoxy-2'-fluoro-2'-C-methylcytidine: a specific inhibitor of hepatitis $C$ virus replication. Antivir Chem Chemother 17, 79-87.

Uebelhoer, L.S., Albariño, C.G., McMullan, L.K., Chakrabarti, A.K., Vincent, J.P., Nichol, S.T., Towner, J.S., 2014. High-throughput, luciferase-based reverse genetics systems for identifying inhibitors of Marburg and Ebola viruses. Antiviral Res 106, 86-94.

World Health Organisation, 2016. Ebola Situation Reports.

Yonezawa, A., Cavrois, M., Greene, W.C., 2005. Studies of ebola virus glycoprotein-mediated entry and fusion by using pseudotyped human immunodeficiency virus type 1 virions: involvement of cytoskeletal proteins and enhancement by tumor necrosis factor alpha. J Virol 79, 918-926. Zhang, J.H., Chung, T.D., Oldenburg, K.R., 1999. A simple statistical parameter for use in evaluation and validation of high throughput screening assays. J Biomol Screen 4, 67-73. 
a.

LASV

protein expression plasmids

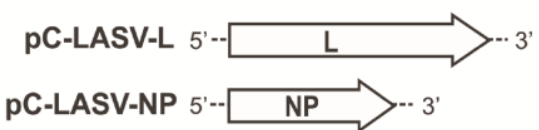

pC-LASV-NP $5^{\prime}--\quad$ NP $>-3^{\prime}$

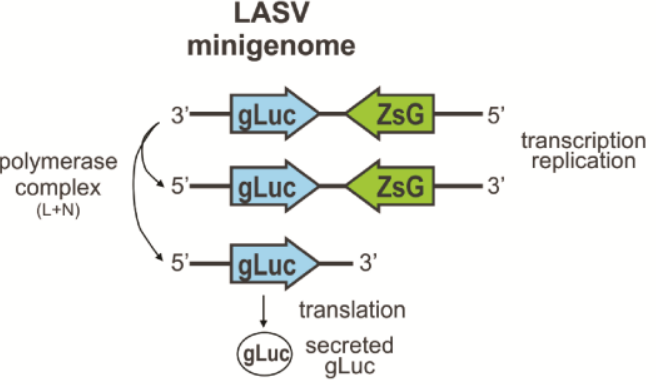

b.

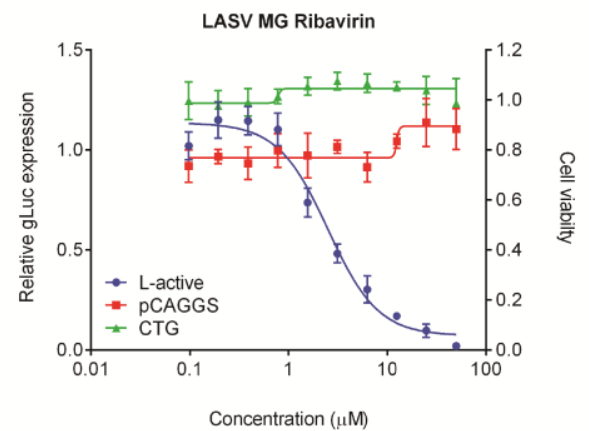

EBOV

protein expression plasmids

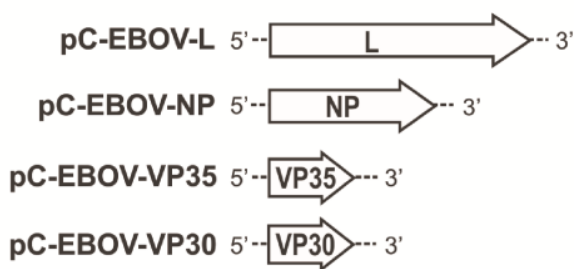

C.

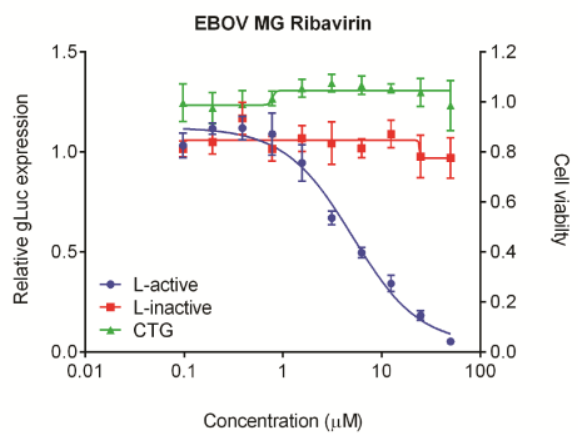

d.

\begin{tabular}{|c|c|c|c|c|c|c|c|c|c|}
\hline \multirow[t]{2}{*}{ Compound } & \multirow[b]{2}{*}{$\mathrm{CC}_{50}$} & \multicolumn{4}{|c|}{ LASV MG * } & \multicolumn{4}{|c|}{ EBOV MG * } \\
\hline & & $\mathrm{EC}_{50}$ & $\mathrm{EC}_{50} \mathrm{BG}$ & $\mathrm{SI}$ & $\mathrm{Sl}_{\mathrm{pol}}$ & $\mathrm{EC}_{50}$ & $\mathrm{EC}_{50} \mathrm{BG}$ & $\mathrm{SI}$ & $\mathrm{SI}_{\text {pol }}$ \\
\hline Ribavirin & $>50$ & 2.51 & $>50$ & $>20$ & $>20$ & 5.04 & $>50$ & $>20$ & $>20$ \\
\hline
\end{tabular}

*All values in $\mu \mathrm{M}$ 
a.
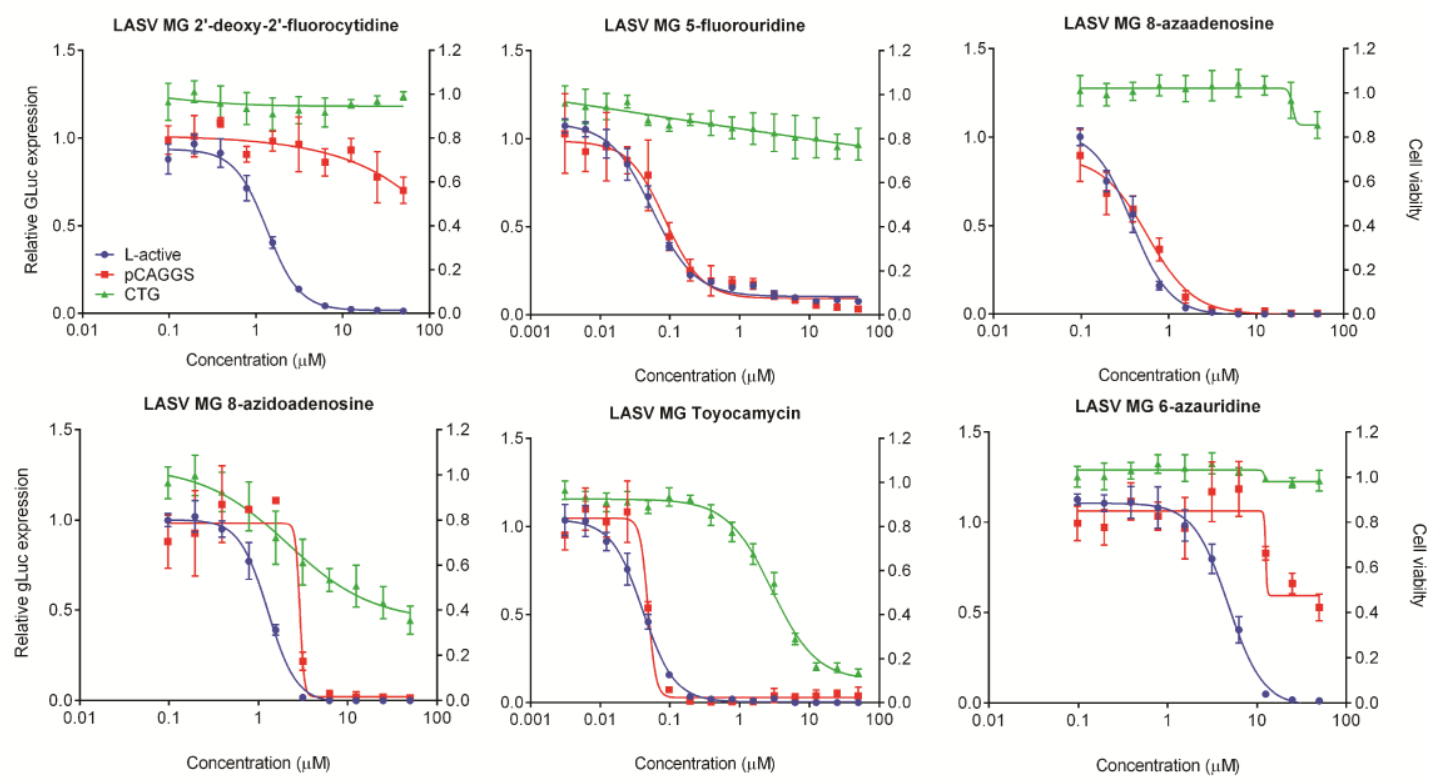

b.
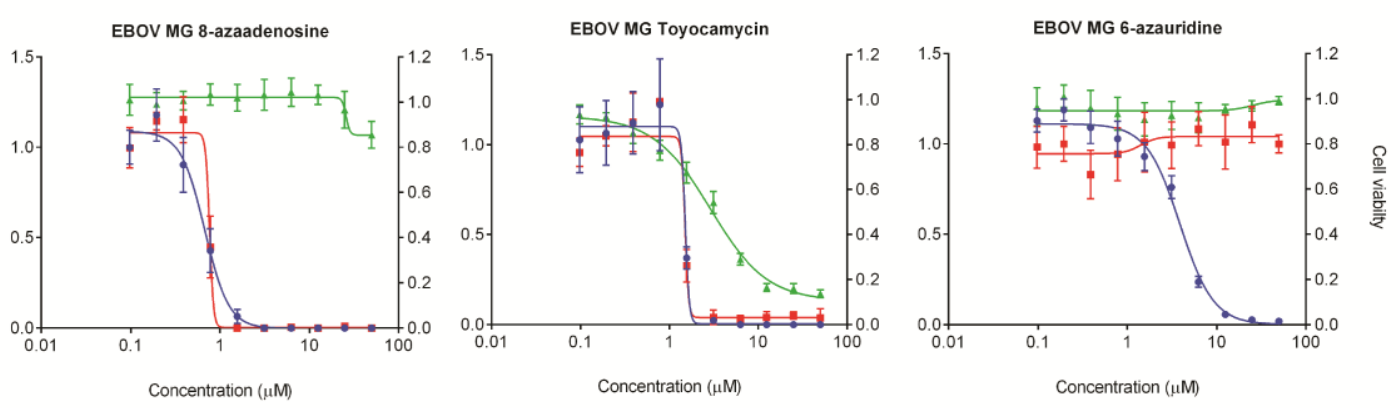

c.

\begin{tabular}{|c|c|c|c|c|c|c|c|c|c|}
\hline \multirow[t]{2}{*}{ Compound } & \multirow[b]{2}{*}{$\mathrm{CC}_{50}$} & \multicolumn{4}{|c|}{ LASV MG * } & \multicolumn{4}{|c|}{ EBOV MG * } \\
\hline & & $\mathrm{EC}_{50}$ & $\mathrm{EC}_{50} \mathrm{BG}$ & SI & $\mathrm{SI}_{\mathrm{pol}}$ & $\mathrm{EC}_{50}$ & $\mathrm{EC}_{50} \mathrm{BG}$ & SI & $\mathrm{Sl}_{\mathrm{po}}$ \\
\hline 2'-deoxy-2'-fluorocytidine & $>50$ & 1.35 & $>50$ & $>37$ & $>37$ & NT & NT & NT & NT \\
\hline 5-fluorouridine & $>50$ & 0.05 & 0.09 & $>1000$ & 2 & NT & NT & NT & NT \\
\hline 8-azaadenosine & $>50$ & 0.38 & 0.58 & $>132$ & 2 & 0.68 & 0.77 & $>74$ & 1 \\
\hline 8-azidoadenosine & 2.14 & 1.28 & 2.90 & 2 & 2 & NT & NT & NT & NT \\
\hline Toyocamycin & 2.88 & 0.04 & 0.05 & 72 & 1 & 1.51 & 1.50 & 2 & $<1$ \\
\hline 6-azauridine & $>50$ & 4.76 & $>50$ & $>11$ & $>11$ & 3.88 & $>50$ & $>13$ & $>13$ \\
\hline
\end{tabular}


a.

rEBOV/ZsG

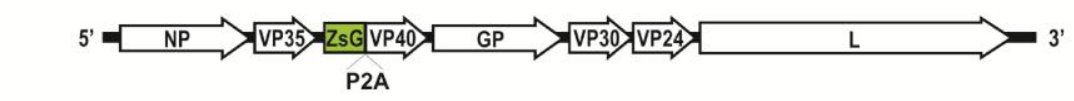

rLASVIZsG

SRNA
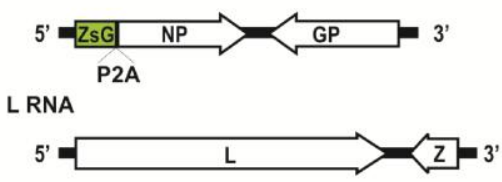

b.

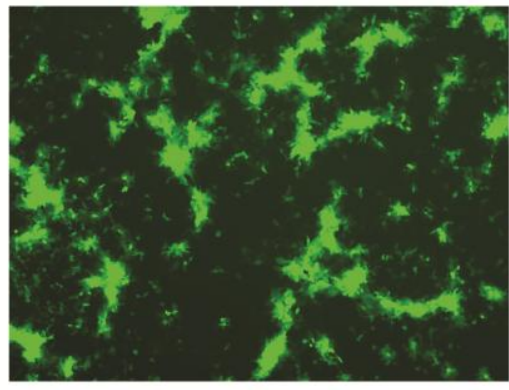

rEBOV/ZsG

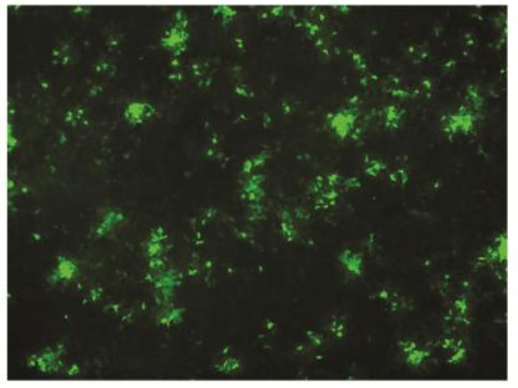

rLASVIZsG c.

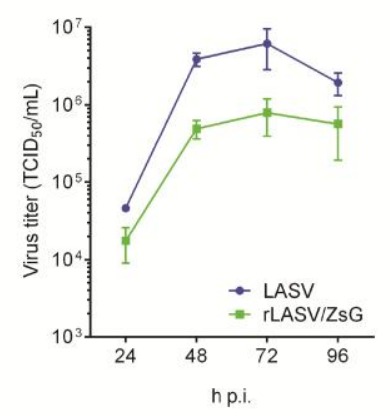

d.

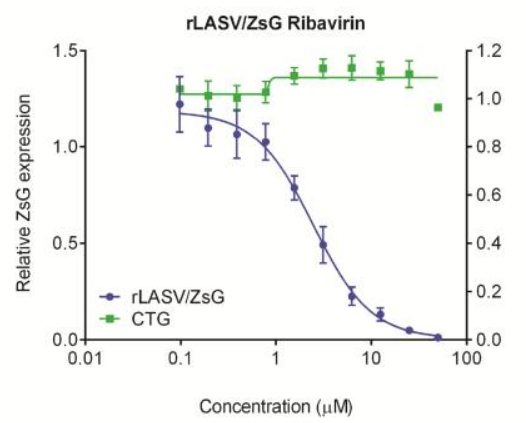

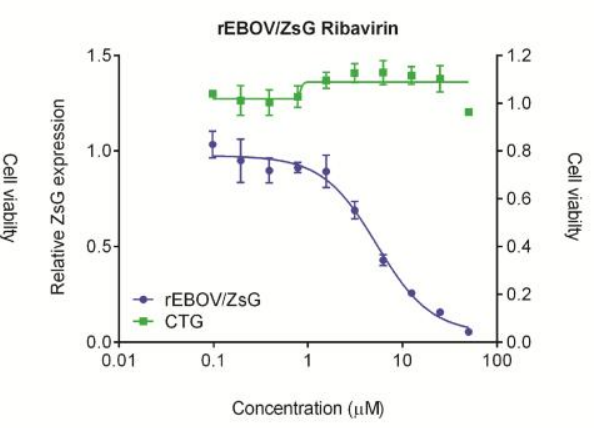

e.

\begin{tabular}{lcccccc}
\hline Compound & & \multicolumn{2}{c}{ rLASV/ZsG $^{*}$} & & \multicolumn{2}{c}{ rEBOV/ZsG* } \\
\cline { 3 - 4 } & $\mathrm{CC}_{50}$ & $\mathrm{SI}$ & & $\mathrm{EC}_{50}$ & $\mathrm{SI}$ \\
\hline Ribavirin & $>50$ & 2.47 & $>20$ & & 5.34 & $>9$ \\
\hline *All values in $\mu \mathrm{M}$ & & & & & &
\end{tabular}


a.
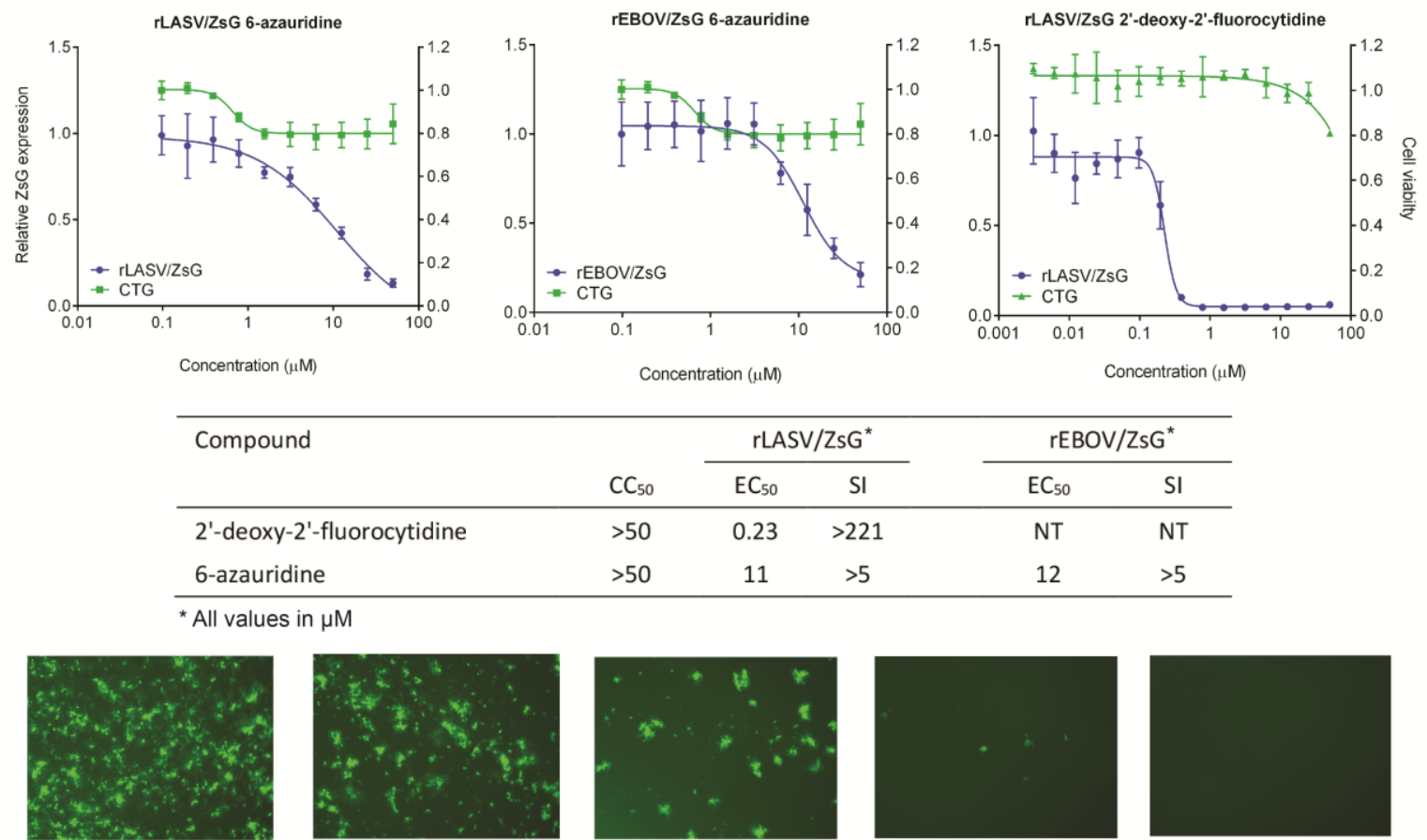

Mock

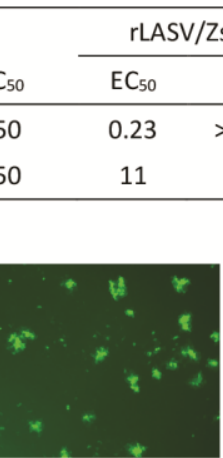

$0.39 \mu \mathrm{M}$

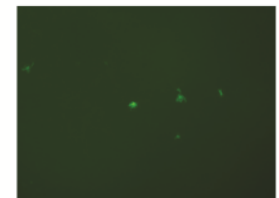

$0.78 \mu \mathrm{M}$

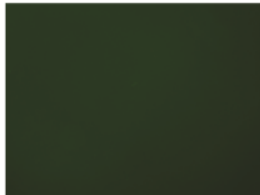

$1.56 \mu \mathrm{M}$

c.

LASV 6-azauridine

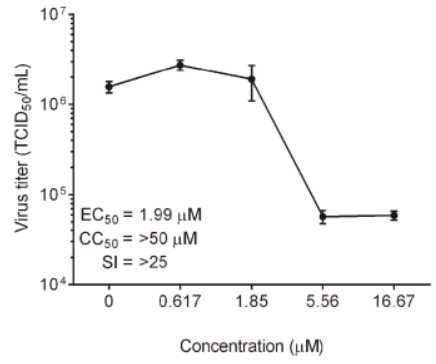

EBOV 6-azauridine

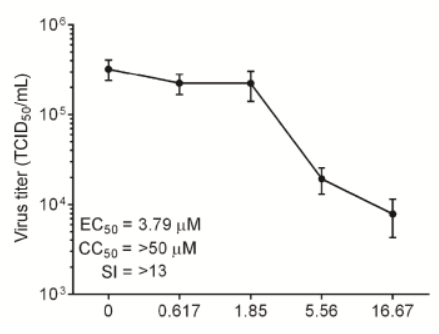

Concentration $(\mu \mathrm{M})$
LASV 2'-deoxy-2'-fluorocytidine

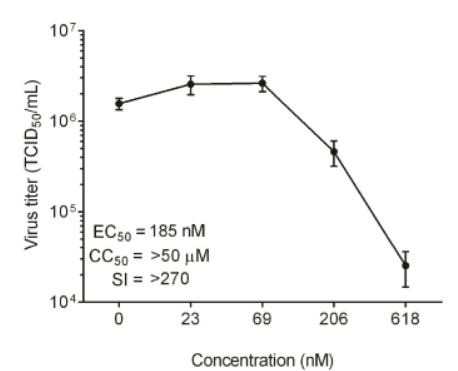

d.<smiles>Nc1ccn([C@@H]2O[C@H](CO)[C@@H](O)[C@H]2F)c(=O)n1</smiles>

2'-deoxy-2'-fluorocytidine<smiles>O=c1cnn([C@@H]2O[C@H](CO)[C@@H](O)[C@H]2O)c(=O)[nH]1</smiles>

6-azauridine 
a.
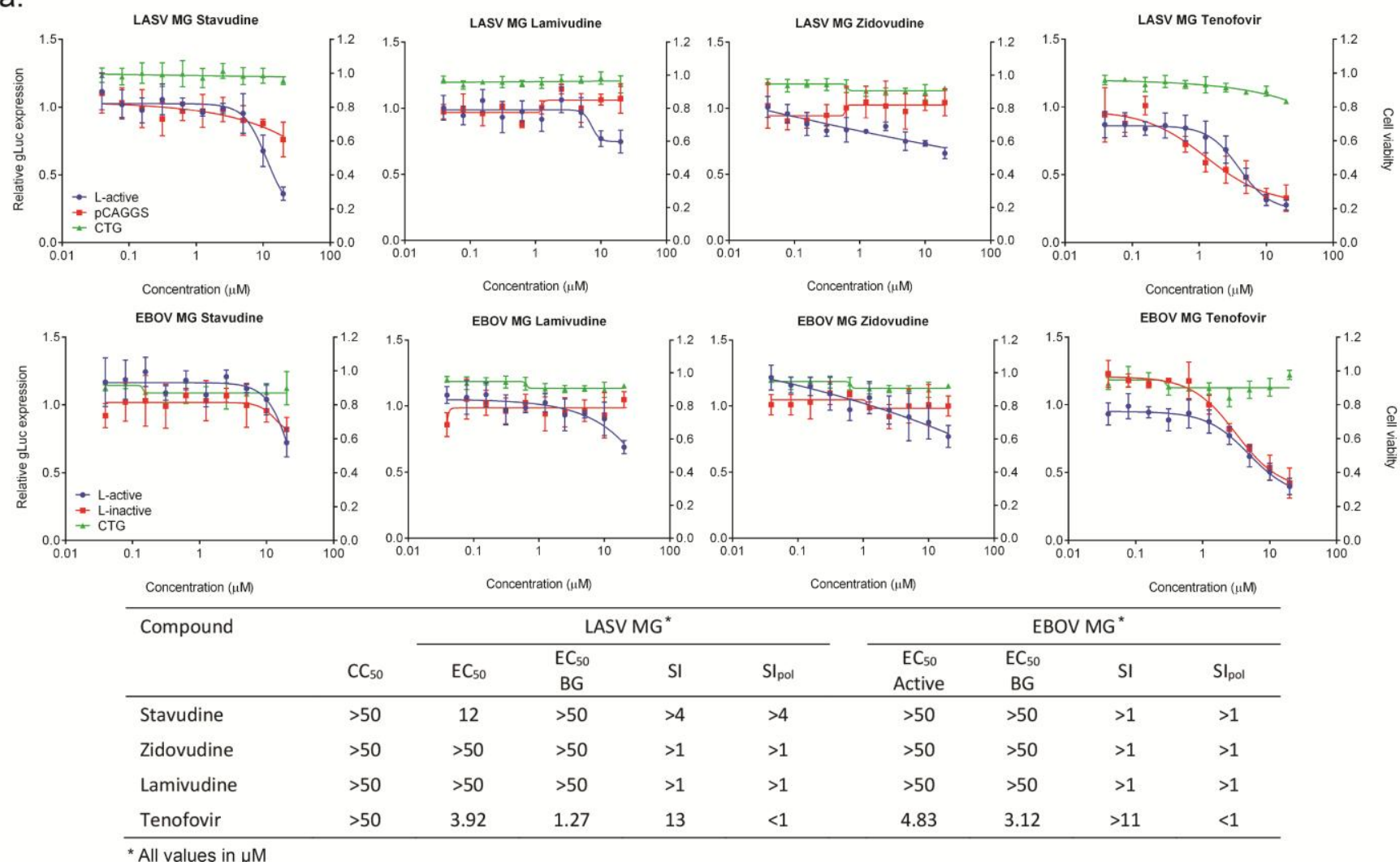

b.
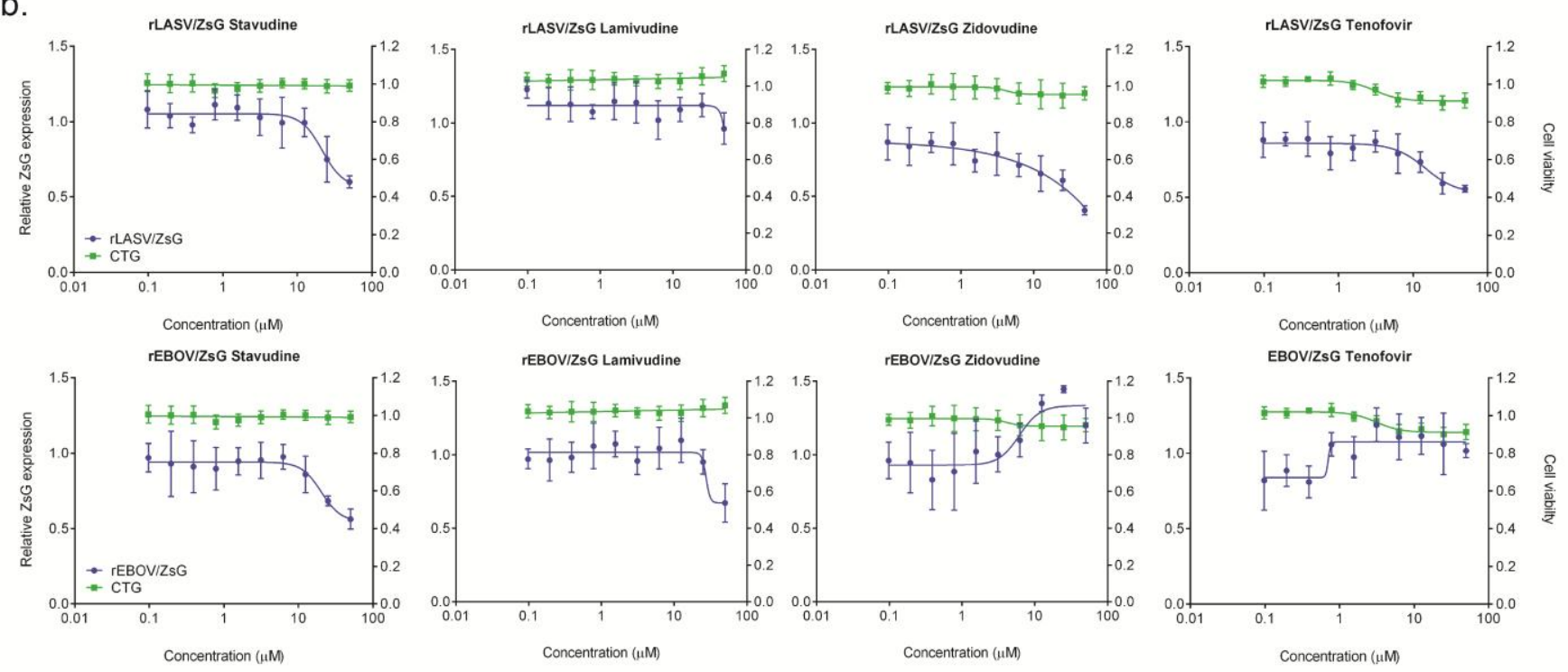

\begin{tabular}{lllllll}
\hline Compound & & \multicolumn{2}{c}{ rLASV/ZsG $^{*}$} & & \multicolumn{2}{c}{ rEBOV/ZsG $^{*}$} \\
\cline { 3 - 4 } \cline { 6 - 7 } & $\mathrm{CC}_{50}$ & $\mathrm{EC}_{50}$ & $\mathrm{SI}$ & & $\mathrm{EC}_{50}$ & $\mathrm{SI}$ \\
\hline Stavudine & $>50$ & $>50$ & $>1$ & & $>50$ & $>1$ \\
Zidovudine & $>50$ & $>50$ & $>1$ & & $>50$ & $>1$ \\
Lamivudine & $>50$ & $>50$ & $>1$ & & $>50$ & $>1$ \\
Tenofovir & $>50$ & $>50$ & $>1$ & & $>50$ & $>1$ \\
\hline
\end{tabular}

* All values in $\mu \mathrm{M}$ 